Jurnal Indonesia Sosial Teknologi: p-ISSN: 2723 - 6609

e-ISSN : 2745-5254

Vol. 2, No. 3 Maret 2021

\title{
MODEL BERORIENTASI OBJEK SISTEM PENDUKUNG KEPUTUSAN PENENTUAN KINERJA KARYAWAN DENGAN METODE ELIMINATION ET CHOIX TRADUISANT LAREALITÉ PADA PERUSAHAAN TELEKOMUNIKASI
}

\section{Lia Purnamasari dan Irman Hariman}

Program Studi Sistem Informasi STMIK LPKIA Bandung, Indonesia

Email: liapurnamas48@gmail.com, irmanhariman@gmail.com

\section{Abstract}

The increasingly competitive competition in the business world has spurred companies to improve the quality of human resources. In its implementation, the selection process for the best employees has not been optimal. The assessment for selecting the best employee may occur subjectively by only paying attention to several aspects of the employee appraisal criteria without looking at other aspects of the criteria. An assessment that has not used a method that can handle priority problems with many criteria. This becomes a problem in determining whether or not someone is selected as the best employee. Therefore, in this scientific journal it is proposed that an employee assessment system be built that can provide optimal alternative solutions for-based decision making Web using the ELECTRE (Elimination Et Choix Traduisant Larealitémethod). This system was developed with modeling using an object-oriented approach with a methodology using Prototype. Meanwhile, the supporting software uses MySQL as a database and the PHP programming language. This system will run on a website that can be accessed intranet on the Local Area Network. Based on the research conducted, this study will produce a performance appraisal application in the management of the value aspect of the criteria that can provide accurate information to managers and assist companies in making employee performance appraisal reports.

Keyword: work stress; work load; work environment; employee performance

\section{Abstrak}

Persaingan dunia bisnis yang makin kompetitif memacu perusahaan untuk meningkatkan kualitas sumber daya manusia. Dalam pelaksanaannya proses pemilihan karyawan terbaik ini belum bisa optimal. Penilaian untuk memilih karyawan terbaik kemungkinan bisa terjadi secara subjektif dengan hanya memperhatikan beberapa aspek kriteria penilaian karyawan tanpa melihat aspek kriteria lainnya. Penilaian yang belum menggunakan suatu metode yang dapat menangani permasalahan prioritas dengan banyak kriteria. Hal ini menjadi sebuah permasalahan untuk menentukan tepat atau tidaknya seseorang terpilih sebagai karyawan terbaik. Karena itu, pada jurnal ilmiah ini diusulkan perlu dibangunnya sebuah sistem penilian karyawan yang dapat memberikan alternatif solusi optimal untuk pengambilan keputusan berbasis Web dengan menggunakan metode ELECTRE (Elimination Et Choix Traduisant Larealité). Sistem ini dikembangkan 
dengan pemodelan yang menggunakan pendekataan Berorientasi Objek dengan metodologi menggunakan Prototype. Sedangkan perangkat lunak penunjang menggunakan MySQL sebagai database dan bahasa pemrograman PHP. Sistem ini akan berjalan pada suatu website yang bisa diakses secara intranet di Local Area Network. Berdasarkan penellitian yang dilakukan penelitian ini akan menghasilkan suatu aplikasi penilaian kinerja dalam pengelolaan nilai aspek kriteria yang dapat memberikan informasi yang tepat terhadap manager dan membantu perusahaan dalam pembuatan laporan penilaian kinerja karyawannya.

Kata kunci: penilaian kinerja karyawan; WEB; prototype; sistem; metode electre.

\section{Pendahuluan}

Karyawan pada suatu perusahaan merupakan aset sangat penting bagi suatu perusahaan dalam usahanya untuk mempertahankan kelangsungan hidup, berkembang, serta memiliki kemampuan untuk bersaing demi mendapatkan laba. Tidak ada satupun perusahaan yang mampu bertahan bilamana perusahaan tersebut tidak memiliki karyawan yang dapat bekerja dengan baik dan maksimal. Demikian halnya bagi perusahaan telekomunikasi yang bergerak di bidang penyelenggara layanan telekomunikasi dan jaringan yang sangat luas di Indonesia (Ruth, 2013). Layanan telekomunikasi tersebut mencangkup sambungan telepon PSTN tidak bergerak dan telepon nirkabel tidak bergerak, komunikasi seluler, layanan jaringan dan interkoneksi serta layanan internet dan komunikasi data. Perusahaan ini juga menyediakan berbagai layanan dibidang informasi, media dan edutainment, termasuk cloud-based dan server managed services, layanan e-payment dan IT enabler, e-Commerce dan layanan portal lainnya (Haris Mz, 2019). Untuk mendukung bisnisnya yang semakin berkembang dengan persaingan yang begitu ketat maka perlu dilakukan pemeliharaan sumber daya manusia agar senantiasa mampu menunjukan kinerja yang meningkat dari waktu ke waktu. Untuk menunjang hal tersebut sehingga diperlukan suatu sistem yang baik untuk memberikan dukungan terhadap manajerial dalam memberikan penilaian yang ebjektif terhadap seluruh karyawan di semua level manajerial (Larasati, 2018).

Berdasarkan hal tersebut maka perlu dibangunnya sebuah sistem penilian karyawan yang dapat memberikan alternatif solusi optimal untuk pengambilan keputusan yang dilakukan oleh pihak Human Resource Development (HRD) dalam memilih karyawan terbaiknya secara objektif. Sistem ini dapat membantu dalam memberikan rekomendasi mengenai penilaian kinerja karyawan kepada pihak HRD berdasarkan kriteria-kriteria yang telah ditentukan. Dengan menggunakan metode Elimination Et Choix Traduisant La Realité (ELECTRE), yang merupakan salah satu metode dalam pengambilan keputusan multikriteria berdasarkan pada konsep outranking dengan membandingkan pasangan alternatif-alternatif berdasarkan setiap kriteria yang sesuai sehingga akan dihasilkan suatu penilaian yang objektif (Andika et al., 2019). Oleh karena itu penggunaan metode ELECTRE sangat sesuai dengan kasus ini terutama dengan banyaknya alternatif pilihan penilaian pegawai berdasarkan kriteria-kriteria yang ada dan digunakan. Metode Elimination Et Choix Traduisant La 
Realité (ELECTRE) diharapkan dapat membantu dalam mengambil keputusan lebih cepat dan sesuai kriteria-kriteria yang sudah ada dan dapat menentukan karyawan yang berprestasi.

\section{Metode Penelitian}

Langkah-langkah yang dilakukan dalam penyelesaian masalah menggunakan metode ELECTRÉ adalah sebagai berikut.

1. Normalisasi matriks keputusan.

Dalam prosedur ini, setiap atribut diubah menjadi nilai yang comparable. Setiap normalisasi dari nilai $x i j$ dapat dilakukan dengan rumus

$$
\begin{aligned}
r_{i j}=\frac{x_{i j}}{\sqrt{\sum_{i=1}^{w_{m}^{m} x_{i j}^{2}}}} & \text { untuk } i \\
& =1,2,3, \ldots, \text { m dan } j \\
& =1,2,3, \ldots, n .
\end{aligned}
$$

Sehingga didapat matriks $\mathrm{R}$ hasil normalisasi,

$$
R=\left[\begin{array}{rrrr}
r_{11} & r_{12} & \ldots & r_{1 n} \\
r_{21} & r_{22} & \ldots & r_{2 n} \\
\vdots & & & \\
r_{m 1} & r_{m 2} & \ldots & r_{m n}
\end{array}\right]
$$

$\mathrm{R}$ adalah matriks yang telah dinormalisasi, dimana $\mathrm{m}$ menyatakan alternatif, $\mathrm{n}$ menyatakan kriteria dan $r i j$ adalah normalisasi pengukuran pilihan dari alternatif ke-i dalam hubungannya dengan kriteria ke-j (Fauzi et al., 2016).

2. Pembobotan pada matriks yang telah dinormalisasi. Setelah dinormalisasi, setiap kolom dan matriks $\mathrm{R}$ dikaitkan dengan bobot-bobot $(w j)$ yang ditentukan oleh pembuat keputusan.

$$
V=R \cdot W
$$

$$
\begin{aligned}
& {\left[\begin{array}{cccc}
v_{11} & v_{12} & \ldots & v_{1 n} \\
v_{21} & v_{22} & \ldots & v_{2 n} \\
\vdots & & & \\
v_{m 1} & v_{m 2} & \ldots & v_{m n}
\end{array}\right]} \\
& =\left[\begin{array}{cccc}
w_{1} r_{11} & w_{2} r_{12} & \ldots & w_{n} r_{1 n} \\
w_{1} r_{21} & w_{2} r_{22} & \ldots & w_{n} r_{2 n} \\
\vdots & & & \\
w_{1} r_{m 1} & r w_{2} r_{m 2} & \ldots & w_{n} r_{m n}
\end{array}\right]
\end{aligned}
$$

Dimana $\mathrm{W}$ adalah

$$
W=\left[\begin{array}{cccc}
w_{1} & 0 & \ldots & 0 \\
0 & w_{2} & \ldots & 0 \\
\vdots & & &
\end{array}\right]
$$

3. Menentukan himpunan concordance dan discordance index. Untuk setiap pasang dari alternatif $\mathrm{k}$ dan $1(\mathrm{k}, \mathrm{l}=1,2,3, \ldots, \mathrm{m}$ dan $\mathrm{k} \neq 1)$ Kumpulan $\mathrm{J}$ kriteria dibagi menjadi dua himpunan bagian, yaitu concordance dan discorcondance. Sebuah kriteria dalam suatu alternatif termasuk concordance jika: $C k l=\{j, v k j \geq v i j\}$, untuk $j=1,2,3, \ldots$ ,$n$ 
Sebaliknya, komplementer dari himpunan bagian concordance adalah himpunan discorcondance, yaitu bila : $D k l=\{j, v k j<v i j\}$, untuk $j=1,2,3, \ldots, n$

4. Menghitung matrix concordance dan discordance.

a. Menghitung matriks concordance Untuk menentukan nilai dari elemen-elemen pada matriks concordance adalah dengan menjumlahkan bobot-bobot yang termasuk pada himpunan concordance, secara matematisnya adalah sebagai berikut:

$$
C_{k l}=\sum_{j \in C_{k l}} w_{j}
$$

b. Menghitung matriks discordance Untuk menentukan nilai dari elemen-elemen pada matriks discordance adalah dengan membagi maksimum selisih kriteria yang termasuk kedalam himpunan bagian discordance dengan maksimum selisih nilai seluruh kriteria yang ada, secara matematisnya adalah sebagai berikut :

$$
d_{k l}=\frac{\max \left\{\left|V_{k j}-V_{l j}\right|\right\}_{j \in D_{k l}}}{\max \left\{\left|V_{k j}-V_{l j}\right|\right\}_{\forall j}}
$$

5. Menentukan matriks dominan concordance dan discordance

a. Menghitung matriks dominan concordance Matriks F sebagai matriks dominan concordance dapat dibangun dengan bantuan nilai threshold, yaitu dengan membandingkan setiap nilai elemen matriks concordance dengan nilai threshold.

$$
C_{k l} \geq \underline{C}
$$

Dengan nilai threshold $(C)$ adalah:

$$
\underline{C}=\frac{\sum_{k=1}^{m} \sum_{l=1}^{m} C_{k l}}{m(m-1)}
$$

Sehingga elemen matriks F ditentukan sebagai berikut:

$$
f_{k l}=\left\{\begin{array}{l}
1, j i k a C_{k l} \geq \underline{C} \\
0, j i k a C_{k l}<\underline{C}
\end{array}\right.
$$

b. Menghitung matriks dominan discordance Matriks G sebagai matriks dominan discordance dapat dibangun dengan bantuan nilai threshold $d$ :

$$
\underline{d}=\frac{\sum_{k=1}^{m} \sum_{l=1}^{m} d_{k l}}{m(m-1)}
$$

Dan elemen matriks $G$ ditentukan sebagai berikut:

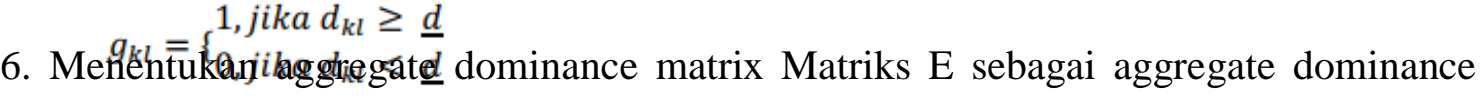
matrix adalah matriks yang setiap elemennya merupakan perkalian antara elemen matriks $\mathrm{F}$ dengan elemen matriks $\mathrm{G}$ yang bersesuaian, secara matematis dapat dinyatakan sebagai berikut:

$$
\mathrm{e}_{\mathrm{kl}}=\mathrm{f}_{\mathrm{kl}} \times \mathrm{g}_{\mathrm{kl}}
$$

7. Eliminasi alternatif yang less favourable Matriks E memberikan urutan pilihan dari setiap alternatif, yaitu bila $e k l=1$ maka alternatif $A k$ merupakan alternatif yang lebih baik daripada $A 1$. Sehingga, baris dalam matriks E yang memiliki jumlah $e k=$ 
1 paling sedikit dapat di eliminasi. Dengan demikian, alternatif terbaik adalah alternatif yang mendominasi alternatif lainnya (Setiyawati et al., 2015).

\section{Hasil dan Pembahasan}

Hasil analisis kebutuhan sistem penentuan peringkat karyawan dengan menggunakan metode Elimination Et Choix Traduisant Larealite, maka diperoleh kebutuhan fungsional bagi sistem yang dapat digambarkan dalam diagram use case (Marlinda, 2016). Use Case menjelaskan fungsional sistem yang akan di terapkan pada perangkat lunak, dengan pendefinisian fungsional yang di lakukan aktor (Pengguna sistem) dan sistem untuk tujuan tertentu. Fungsi yang digunakan pada sistem perangkat lunak ini merupakan fungsi-fungsi yang ditentukan melalui tahapan-tahapan dari metode ELECTRE (Rochmatin, 2019). Fungsi tersebut nantinya akan diadopsi menjadi suatu fungsi pada perangkat lunak dan menjadi suatu method yang terdapat pada diagram kelas berupa operasi-operasi perangkat lunak dari mulai penentuan kriteria dan parameter penilaian sampai proses perhitungan dan berakhir adalah proses penentuan kinerja karyawan yang semuanya tersaji dalam aplikasi berbasis web (Asriyanik \& Isa, 2018).

Dengan aplikasi ini penilaian kinerja karyawan dengan parameter penilaian yang jadikan standar tidak memungkinkan lagi terjadi penilaian yang tidak objektif terjadi. Berikut adalah fungsionalitas sistem yang diperlukan dalam membangun aplikasi. Berikut Fungsionalitas dari sistem yang dikembangkan :
a. Kelola data kriteria Penilaian
b. Pembobotan Kriteria
c. Menampilkan Hasil Rangking
d. Cetak Laporan Karyawan Terbaik
e. Penentuan Penilaian Kinerja
f. Olah Data Karyawan

Berikut aktor yang terlibat dalam sistem penentuan penilaian karyawan terbaik, yaitu :
a. Kepala HRD
b. Staf HRD

Berdasarkan fungsioalitas sistem dan aktor yang berinteraksi dengan sistem tersebut kemudian digambarkan dalam diagram usecase, sebagai berikut: 


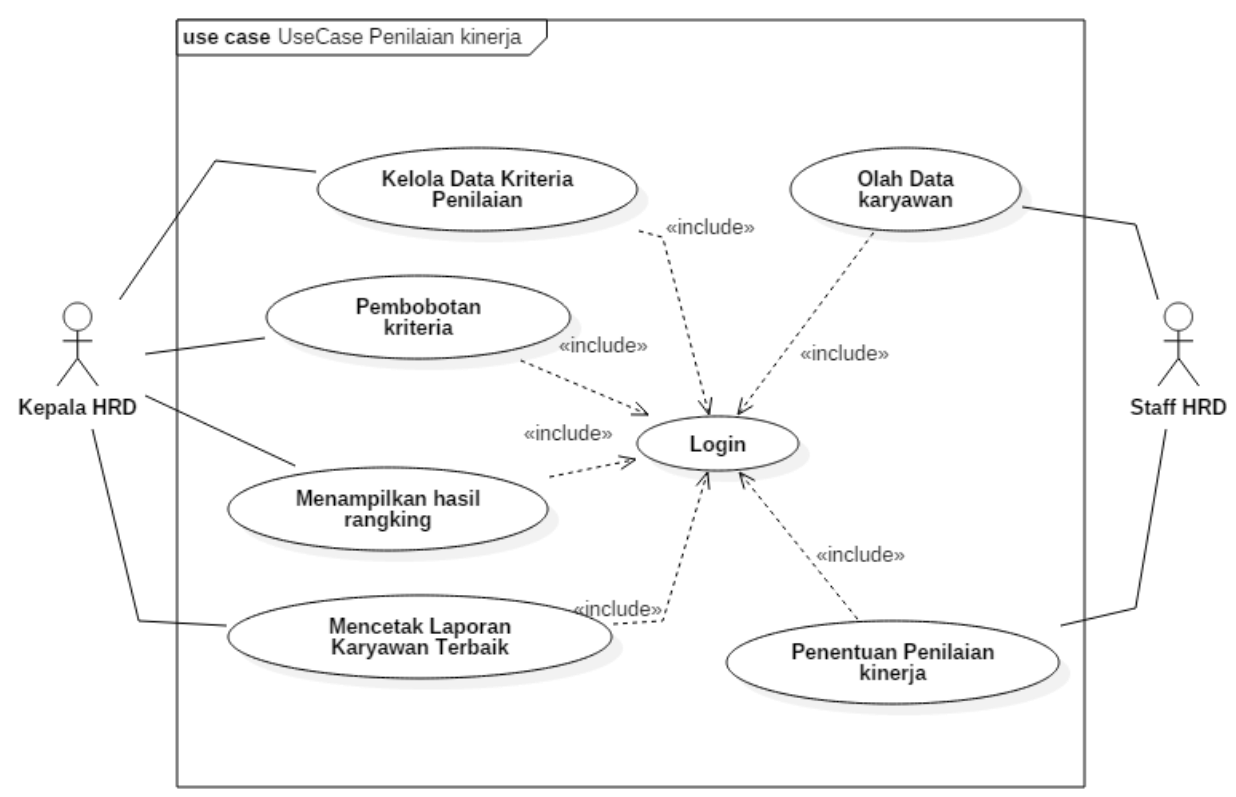

Gambar 1.UCD Sistem Penentuan Kinerja

Untuk penjelasan mengenai proses bisnis sistem yang dibangun dalam penentuan kriteia penilaian karyawan terbaik dapat terlihat pada diagram aktivitas. Activity Diagram dibawah ini menggambarkan sistem berjalan dengan fungsi-fungsi yang telah digambarkan pada use case diagram diatas, sehingga sistem lebih nampak lebih nyata saat nanti diimplementasikan kedalam perangkat lunaknya. Semua proses harus sesuai dengan tahapan metode ELECTRE yang dijadikan acuannya (Simangunsong \& Sinaga, 2019). Berikut ini diagram aktivitasnya :

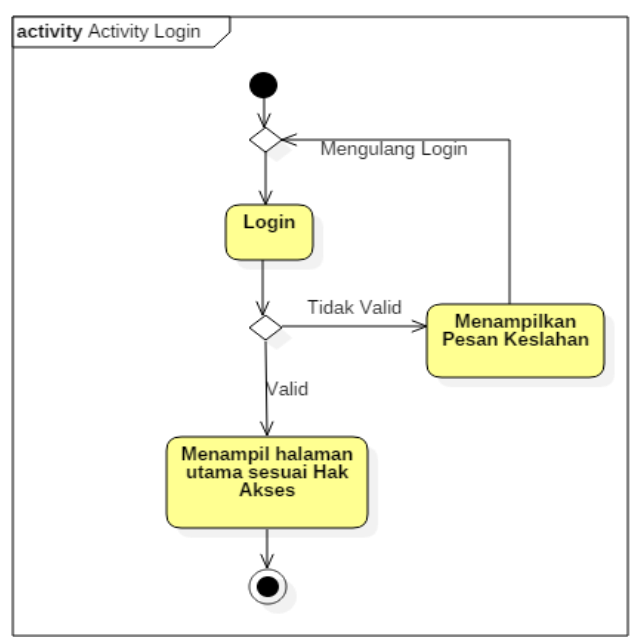

Gambar 2. AD Login

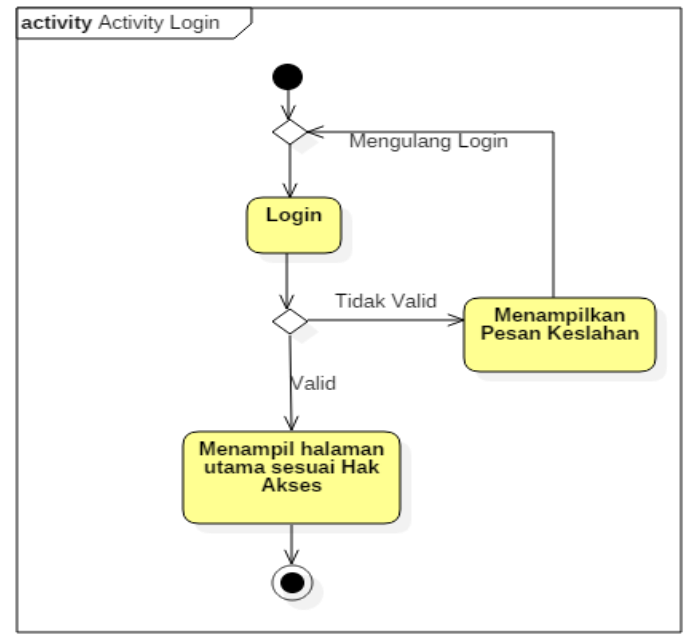

Gambar 3. AD Data Karyawan 
Model Berorientasi Objek Sistem Pendukung Keputusan Penentuan Kinerja Karyawan dengan Metode Elimination Et Choix Traduisant Larealité pada Perusahaan

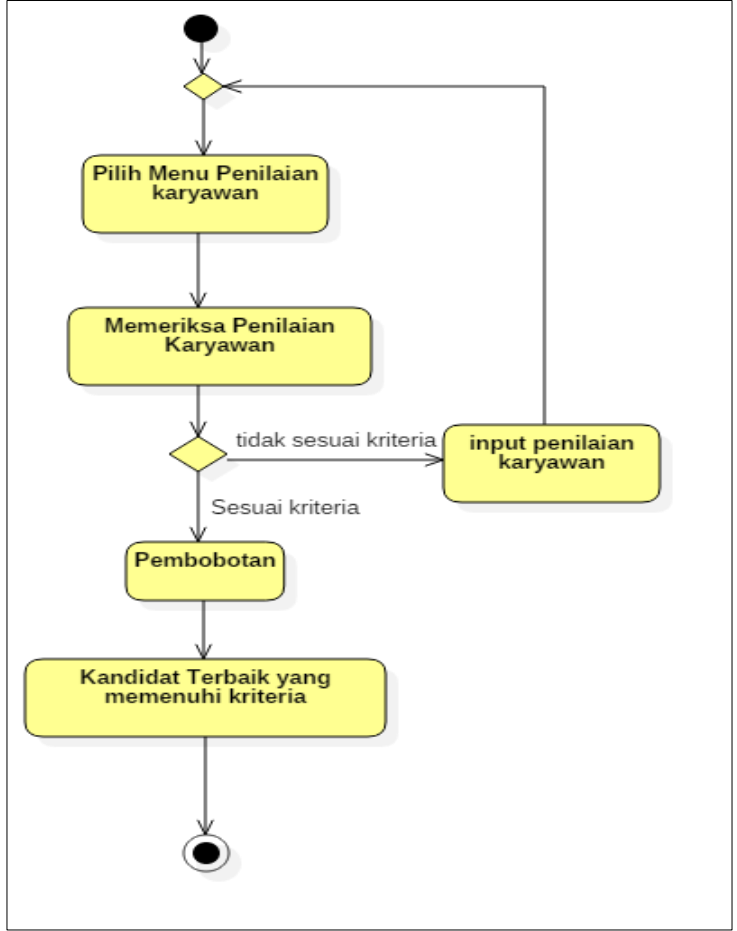

Gambar 4. AD Pembobotan Kriteria Terbaik

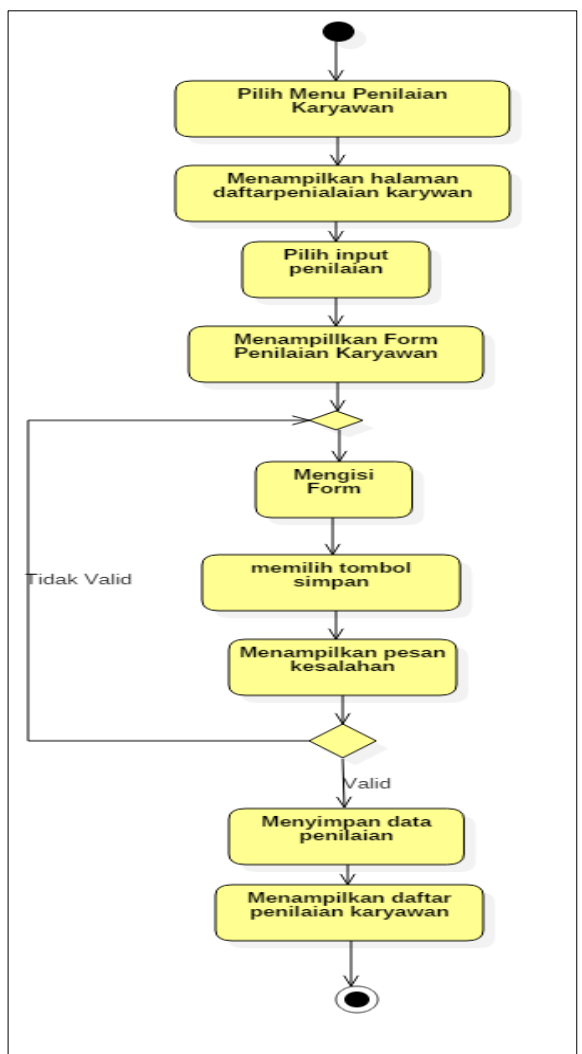

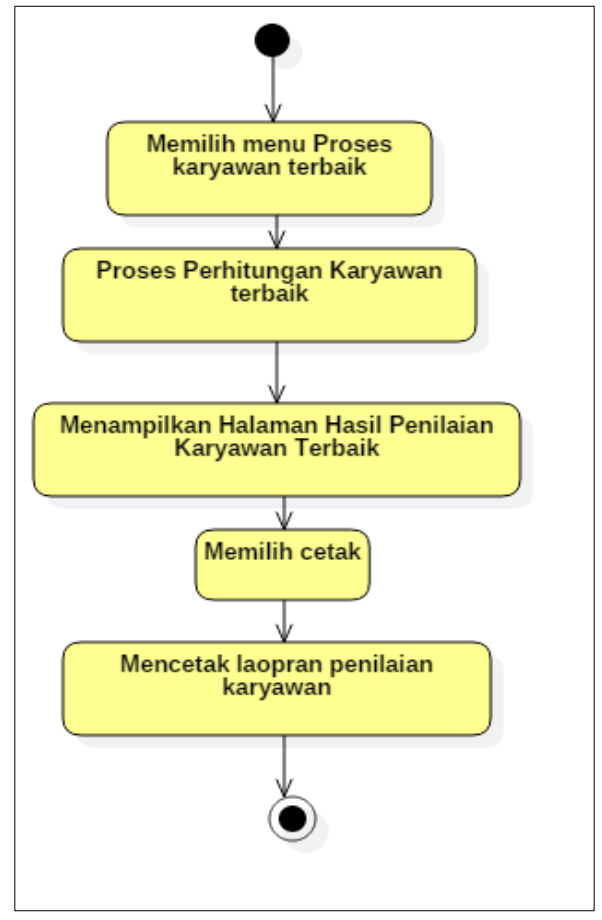

Gambar 5. ADRangking Karyawan

Gambar 6. AD Penentuan Penilaian Kinerja 
Untuk memberikan penjelasan yang lebih jelas mengenai interaksi yang terjadi dalam sistem ini maka perlu di buat diagram kelas untuk menunjukan keterhubungan antar kelas yang terlibat yang lengkap dengan methode yang dimiliki kelas-kelas tersebut. Dengan diagram kelas tersebut metode Elimination Et Choix Traduisant Larealite (ELECTRE) menjadi lebih jelas terkait dengan data dan proses penilaian kinerja karyawan yang akan terjadi dalam perangkat lunak.

Hasil yang dikeluarkan dan ditampilkan dalam perangkat lunak tersebut akan nampak pada methode yang terdapat pada kelas diagram ini. Pada diagram kelas ini terdapat 8 kelas yang saling berinterksi dalam proses pengolahan data penilaian kinerja karyawan. Untuk lebih jelasnya mengenai kelas diagram yang dibuat, berikut rancangan kelas diagram yang akan diimplementasikan kedalam perangkat lunak yang dimaksudkan (Salahudin \& Rosa, 2013).

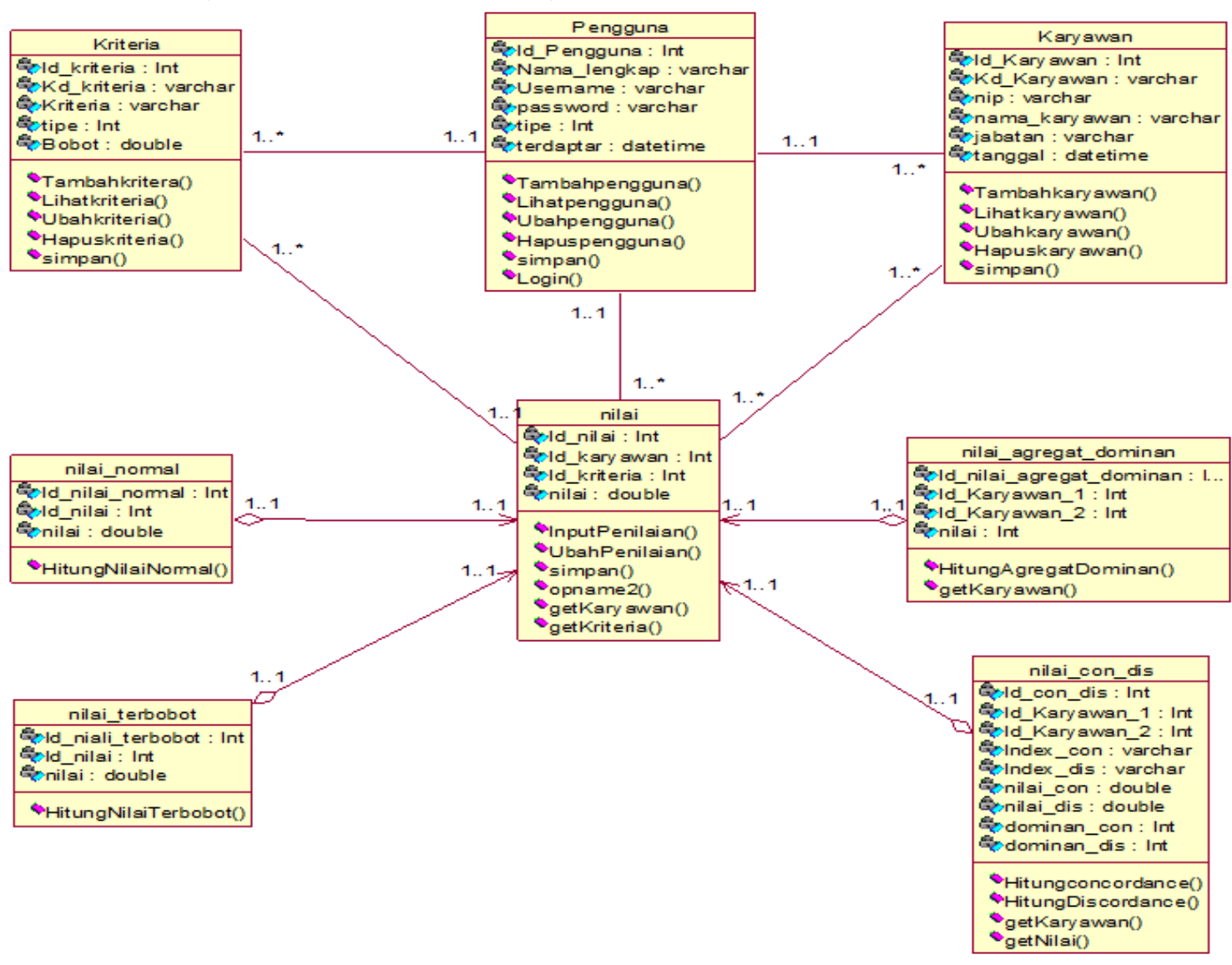

Gambar 8. Class Diagram Sistem Penentuan Kinerja Karyawan

\section{Kesimpulan}

Berdasarkan analisis permasalahan serta pembahasan yang dilakukan dalan peneltitian dan pengujian sistem informasi penilaian kinerja karyawan yang dilakukan, maka dapat diambil kesimpulan sistem infromasi penilaian kinerja karyawan yang telah dibuat mampu memberikan kemudahan saat digunakan untuk melakukan penilaian karyawan yang terbaik dengan lebih objektif. Sistem yang telah dibuat membantu 
Model Berorientasi Objek Sistem Pendukung Keputusan Penentuan Kinerja Karyawan dengan Metode Elimination Et Choix Traduisant Larealité pada Perusahaan Telekomunikasi

memudahkan dalam mengukur parameter untuk menentukan karyawan yang terbaik. Dibangunnya sistem ini berbasis web dengan menggunakan framework tentunya membuat sistem lebih dinamis dan menarik sehingga tidak menjadi kerumitan tersendiri bagi pengguna sekalipun pengguna yang baru mengenal sistem ini. 


\section{Bibliography}

Andika, B., Winata, H., \& Ginting, R. I. (2019). Sistem Pendukung Keputusan Menentukan Duta Sekolah untuk Lomba Kompetensi Siswa Menggunakan Metode Elimination Et Choix Traduisant la Realite (Electre). Jurnal SAINTIKOM (Jurnal Sains Manajemen Informatika Dan Komputer), 18(1), 47-54.

Asriyanik, A., \& Isa, I. G. T. (2018). Rancang Bangun Sistem Layanan Administrasi Berbasis Website Pada Fakultas Sains Dan Teknologi Universitas Muhammadiyah Sukabumi (Ummi). Santika: Jurnal Ilmiah Sains Dan Teknologi, 8(1), 655-664.

Fauzi, W., Informatika, P. S., Jenderal, U., \& Yani, A. (2016). Sistem pendukung keputusan penerima bantuan dana rutilahu dengan menggunakan metode electre 1. Semin. Nas. Teknol. Inf. Dan Komun, 2016, 2089-9815.

Haris Mz, A. (2019). Pengaruh Motivasi Dan Disiplin Kerja Terhadap Kinerja Karyawan Pt. Telkom Tbk, Wilayah Telekomunikasi Jember. Universitas Muhammadiyah Jember.

Larasati, S. (2018). Manajemen Sumber Daya Manusia. Deepublish.

Marlinda, L. (2016). Sistem pendukung keputusan pemilihan tempat wisata yogyakarta menggunakan metode ELimination Et Choix Traduisant La RealitA (ELECTRE). Prosiding Semnastek.

Rochmatin, S. M. (2019). Sistem pendukung keputusan pemilihan makanan sehat untuk penderita Hipertensi menggunakan metode Elemination Et Choix Traduisant La Realite (ELECTRE). UIN Sunan Ampel Surabaya.

Ruth, E. (2013). Deskripsi Kualitas Layanan Jasa Akses Internet di Indonesia dari Sudut Pandang Penyelenggara. Buletin Pos Dan Telekomunikasi, 11(2), 137-146.

Salahudin, M., \& Rosa, A. S. (2013). Rekayasa Perangkat Lunak Terstruktur dan Berorientasi Objek. Bandung: Informatika.

Setiyawati, A., Janu, S., \& Mirza, Y. (2015). Sistem Pendukung Keputusan Pembelian Barang Menggunakan Metode Electre. Tersedia: Http://Ppta. Stikom. Edu/Upload/Upload/File/04410100017Makalah. Pdf [12 Mei 2012].

Simangunsong, P. B. N., \& Sinaga, S. B. (2019). Sistem Pendukung Keputusan Menentukan Dosen Berprestasi Tingkat Kopertis Wilayah I Dengan Metode Electre Berbasis Web. Jurnal Teknovasi: Jurnal Teknik dan Inovasi, 6(3), 63-74. 